\title{
Activity of nanostructured C@ETS-10 sorbent for capture of volatile radioactive iodine from gas stream
}

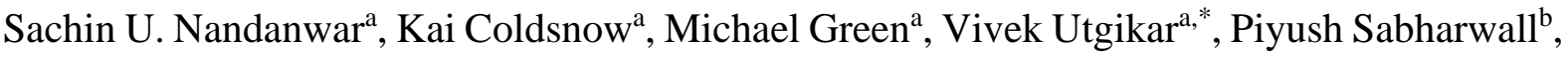
D. Eric Aston ${ }^{\mathrm{a}}$

${ }^{a}$ Department of Chemical and Materials Engineering, University of Idaho, Moscow, Idaho 83844-1021, United States

${ }^{b}$ Idaho National Laboratory, Idaho Falls, Idaho 83415, United States

\begin{abstract}
ETS-10 supported hollow carbon nanostructured polyhedron adsorbent, C@ETS-10, was synthesized by wet impregnation method to evaluate removal of iodine from off-gas stream from a used nuclear fuel reprocessing operation. The characteristics of the adsorbent were investigated by various techniques such as transmission electron microscopy (TEM), scanning electron microscopy-energy dispersive spectroscopy (SEM-EDS), powder X-ray diffraction (P-XRD) and thermogravimetric analysis (TGA), revealing uniform hollow carbon nanostructured polyhedrons with particle size 10-30 nm supported onto ETS-10. The total BET surface area of $10 \mathrm{wt} \%$ C@ETS-10 adsorbent was $149 \mathrm{~m}^{2} \mathrm{~g}^{-1}$. The performance of C@ETS10 nanostructured adsorbent for capture of volatile iodine from gas stream was determined as a function of parameters such as the carbon loading, operating temperatures and empty bed contact time (EBCT). Observed sorption capacity of adsorbent was $28.9 \mathrm{mg} \mathrm{g}^{-1}$ of volatile iodine at $20^{\circ} \mathrm{C}$ without any chemical reaction with sorbent. The maximum dynamic capacity of a column of 10 wt \% C@ETS-10 was calculated to be $40 \mathrm{mg} \mathrm{g}^{-1}$. The nanostructured adsorbent has potential to capture environmental impact of radionuclide off-gas emission from nuclear industry.
\end{abstract}


Keywords: Hollow carbon, ETS-10, Nanosorbent, Volatile iodine, Adsorption, Capacity of sorbent

*Corresponding author:

Department of Chemical and Materials Engineering, University of Idaho 875 Perimeter Dr.; MS 1021; Moscow, ID 83844-1021, USA. Tel.: +1-208-885-6970, Fax: +1-208-885-7462; Email address: vutgikar@uidaho.edu (V. Utgikar).

\section{Introduction}

Nuclear energy is projected to grow continuously worldwide to meet the future energy demands without incurring emissions of greenhouse gases. Nuclear energy is a safe, clean and inexpensive primary energy source, but the faces major issues and concerns associated with nuclear waste management [1]. Strontium-90 $\left({ }^{90} \mathrm{Sr}\right)$ fission products, Technetium-99 $\left({ }^{99} \mathrm{TC}_{\mathrm{C}}\right)$, Caesium-137 $\left({ }^{137} \mathrm{Cs}\right)$, lanthanides, minor actinides and volatile radionuclides are among the major components of concern present in the waste streams from nuclear operations [2]. Gaseous volatile radionuclides are released primarily during the aqueous reprocessing of the used nuclear fuels and tend to leave as off-gas, which contains iodine $\left({ }^{129} \mathrm{I}\right)$, krypton $\left({ }^{85} \mathrm{Kr}\right)$, tritium $\left({ }^{3} \mathrm{H}\right)$, carbon $\left({ }^{14} \mathrm{C}\right)$ and xenon. Among these contaminants iodine isotopes, ${ }^{129} \mathrm{I}$ and ${ }^{131} \mathrm{I}$ exist as iodate or iodide species; are mobile and highly volatile contaminates that can diffuse into the atmosphere. The main concerns related to the volatile radionuclides emissions are the health effects associated with the isotopes $[3,4] .{ }^{129} \mathrm{I}$ is a long-lived isotope (half-life of $1.57 \mathrm{x}$ $10^{7}$ years) and ${ }^{131}$ I short-lived isotope (half-life of 8.02 days) that tend to bioaccumulate, concentrating in the thyroid glands and affecting the biometabolism in humans [2]. Therefore, it is necessary to capture and sequester these contaminants to protect human health and associated environmental concerns. 
Environmental Protection Agency (EPA) 40 CFR 190 regulation requires capture and immobilization of greater than 99.4 mass \% of iodine emissions due to the high vapor pressure and adverse health effects of gaseous iodine [5]. The removal of iodine from gaseous streams is accomplished mainly by using liquid absorption, dry dedusting, precipitation, and adsorption [6]. In recent years, adsorption onto a porous adsorbent has been the primary choice for the removal of radioactive iodine gas due to its advantages that include reliability, simplicity and low operating costs [7]. Previously, several sorbents has been investigated to trap the iodine which includes activated carbon [8,9], silver-exchange zeolite [10], $\mathrm{AgNO}_{3}$-impregnated silica and alumina $[11,12]$, silver-functionalized silica aerogels [13], silver-exchanged titania (ETS10) [14], chalcogen-based aerogel [15-18], monolithic aerogels of polymeric organic framework [19], and metal organic frameworks [20-24].

Lee and Park [8] studied the adsorption capacity of base carbon and 2\% TEDA impregnated carbon for elemental iodine and methyl iodide. They concluded that DubininAstakhov (DA) isotherm provided the best description for the adsorption of elemental iodine and methyl iodide on various carbons. Gan et al. [9] studied adsorption and catalytic decomposition of methyl bromide (MeBr) and methyl iodide (MeI) on activated carbon through batch experiments. Centaur carbon showed promising results for adsorption of $\mathrm{MeBr}$ and $\mathrm{MeI}$ at low concentrations. Park et al. [10] studied the adsorption capacity of various adsorbents including silver ion-exchanged zeolite $(\mathrm{AgX})$, zeocarbon and activated carbon for adsorption of methyl iodide from simulated off-gas stream. Silver ion-exchange adsorbent with $10 \mathrm{wt} \%$ silver showed effective removal of methyl iodide at high temperature $\left(380^{\circ} \mathrm{C}\right)$. Riley et al. [1517] and Surahmanyam et al. [18] synthesized chalcogen-based aerogels, polyacrylonitrilechalcogel hybrid and chalcogenide as sorbents for remediation of radioactive iodine, respectively. Zeng et al. [20] synthesized Zn-lactate connected by organic group (pybz) forming the double walls, which showed higher $\mathrm{I}_{2}$ affinity as compared to zeolite $13 \mathrm{X}$ and 
activated carbon. Sava et al. $[2,21]$ developed the zeolitic imidazolate framework-8 (ZIF-8) and MOF-containing-glass composite material (GCM) waste forms for safe iodine encapsulation. Hughes et al. [22] reported the iodine adsorption capacity of zeolite imidazolate framework- 8 . The results suggested that before thermal treatment, 0.17 and 0.59 mass $\%$ of $\mathrm{I}_{2} / \mathrm{Zn}$ was observed on the surface and inside the cage, respectively. After thermal treatment, 0.59 mass $\%$ of $\mathrm{I}_{2} / \mathrm{Zn}$ was observed on cage. Recently, Massasso et al. [24] synthesized nanocomposites based Hodmann-type structure of $\mathrm{Ni}^{\mathrm{II}}(\mathrm{pz})\left[\mathrm{Ni}^{\mathrm{II}}(\mathrm{CN})_{4}\right](\mathrm{pz}=$ pyrazine$)$ into silica or porous glass by sequential coordination of the molecular precursor into the pores of the functionalized matrices. The uniform spherical sized of $\mathrm{Ni}^{\mathrm{II}}(\mathrm{pz})\left[\mathrm{Ni}^{\mathrm{II}}(\mathrm{CN}) 4\right]$ in the range of 3-6 $\mathrm{nm}$ had a maximum adsorption capacity $1.75 \mathrm{mmol} \mathrm{g}^{-1}$ from cyclohexane solution.

Despite the extensive information, basic need still exists for the development of new and economical adsorbent for capture of iodine. Therefore, the two basic materials, carbon and Engelhard Titanosilicate-10 (support) were selected. Carbon nanostructures have attracted considerable attention due to their unique structural and physicochemical properties [25]. The hollow nanoscale structure of carbon is especially attractive for use as catalyst supports, membranes, adsorption and related materials. Engelhard Titanosilicate, ETS-10, is a new class of molecular sieves, hydrothermally invented by Kuznicki in 1989 [26]. The framework of ETS-10 consists of corner-sharing $\mathrm{TiO}_{6}$ octahedrally and $\mathrm{SiO}_{4}$ tetrahedrally and requires the two counter balancing cation per titanium [27]. The synthesis of ETS-10 has become an area of great interest from a scientific as well as an industrial point of view, due to its physical and chemical properties. It has the uniform pore size of $\sim 8 \AA$ and it is thermally stable in air up to $600{ }^{\circ} \mathrm{C}$. ETS-10 has potential for application in the field of photochemistry, adsorption, gas separation or purification, catalysis, membrane separation process and ion exchange.

In this work we describe for the first time removal of gaseous phase volatile iodine using ETS-10 supported hollow carbon nanostructured polyhedron, C@ETS-10, at near 
atmospheric temperature and pressure. Our work is not only focused on preparation of novel adsorbent but also optimization of process parameters for the capture of volatile iodine from gas stream. The performance of nanostructured adsorbent - C@ETS-10 prepared via wet impregnation method - was studied with respect to parameters such as synthesis parameters, operating temperature, carbon loading and EBCT. The objective of this work is to investigate the capture of volatile iodine from gas stream using hollow carbon nanostructured polyhedron.

\section{Materials and methods}

\subsection{Materials}

Reagents needed - sodium silicate solution $\left(28.6 \% \mathrm{SiO}_{2}, 8.82 \% \mathrm{Na}_{2} \mathrm{O}, 62.58 \% \mathrm{H}_{2} \mathrm{O}\right)$, calcium carbide, nickel dichloride hexahydrate, titanium dioxide powder, elemental iodine (LR grade), sodium chloride, potassium chloride, tetrahydrofuran, THF and nitric acid (AR grade) - were obtained from Fisher Scientific, USA. Ludox HS-40 colloidal silica was purchased from Sigma-Aldrich, USA. Nitrogen, research grade (99.99\% purity) was supplied by Airgas, USA. All chemicals and gas was used without any further purification. De-ionized water (Elga, Pure Lab, USA) was used throughout the experiments for preparing all the aqueous solutions.

\subsection{Synthesis of C@ETS-10}

Active C@ETS-10 nanostructured adsorbent/nanosorbent was prepared as previously described [28]. The hollow carbon nanostructure polyhedron (C) and ETS-10 using $\mathrm{TiO}_{2}$ were synthesized by methods reported elsewhere (see appendix A) [29, 30]. C@ETS-10 was prepared by transferring the carbon nanoparticles onto the ETS-10 support to maintain the homogeneous distribution by wet impregnation method. Uniform carbon nanoparticles were added into $100 \mathrm{~mL}$ tetrahydrofuran (THF) and the mixture was sonicated for 45 min to obtain a uniform dispersion. Appropriate quantity of ETS-10 was added under stirring into the dispersion to obtain the desired carbon loading (3-30)wt \% on the C@ETS-10 adsorbent. The 
mixture was mechanically stirred for $12 \mathrm{~h}$, and dried at room temperature. A dark gray colored powder was formed. The C@ETS-10 was pelletized with addition of $1.5 \mathrm{~g}$ of HS-40 colloidal silica. The mixture was homogenized, followed by compression in a pellet press for $5 \mathrm{~min}$. The cake was crushed and 5-20 mesh size pellets were formulated.

\subsection{Iodine capture experiment set-up}

The experimental setup for capture of iodine from gas stream is shown in Fig. 1. The prepared C@ETS-10 adsorbent (1.0 g) was packed in a 1 inch inside diameter and 12 inch height jacked column made of pyrex glass to avoid any adsorption on metal surface and metal corrosion. Two g elemental iodine (nonradioactive) was placed in a $25 \mathrm{~mL}$ jacked iodine glass vaporizer, where nitrogen purge served as the carrier gas for iodine vapor. The temperatures of iodine vaporizer $\left(40 \pm 2{ }^{\circ} \mathrm{C}\right)$ and adsorption column $\left(10-60^{\circ} \mathrm{C}\right)$ were maintained by circulating the water through the jacket from two different temperature controlled water baths. The experiments were performed at atmospheric pressure. Carrier gas nitrogen was flowed through adsorbent loading column at a flow rate of $130 \mathrm{~mL} \mathrm{~min}^{-1}$ to establish flow pattern through the column for 5 min prior to starting the carrier gas flow through the iodine vaporizer at $20 \mathrm{~mL}$ $\min ^{-1}$, yielding a total flow rate of $150 \mathrm{~mL} \mathrm{~min}^{-1}$. The partial pressure of elemental iodine in the gas was $0.025 \pm 2 \mathrm{~mm} \mathrm{Hg}$ (concentration $-32 \pm 3 \mathrm{ppm}$ ). The residence time in the nanostructured adsorbent column was $1.4 \mathrm{sec}$. Removal efficiency of adsorbent was determined by analyzing the iodine concentrations in inlet and outlet streams. Iodine analysis was performed by trapping iodine in de-ionized water (solubility of iodine in water $1 \mathrm{~g} / 3450 \mathrm{~mL}$ at $20{ }^{\circ} \mathrm{C}$ ) by passing the streams through bubblers (bubbler- 1 for inlet, and bubblers 2 and 3 for outlet). Complete trapping of iodine in bubbler 2 was confirmed by the absence of iodine in bubbler 3. The iodine trap water was analyzed by the Leuco Crystal Violet (LCV) method using Thermo Scientific Evolution 60S UV-Visible Spectrophotometer. The capacity of the synthesized sorbent was calculated using following equation: 


$$
q=\int_{0}^{V} \frac{\left(C_{0}-C_{\mathrm{e}}\right)}{M} d V
$$

where $q$ is the adsorption capacity $\left(\mathrm{mol} \mathrm{g}^{-1}\right), C_{0}\left(\mathrm{~mol} \mathrm{~L}^{-1}\right)$ and $C_{\mathrm{e}}\left(\mathrm{mol} \mathrm{L}^{-1}\right)$ are the inlet and outlet concentrations, respectively, $V$ is the total volume processed at breakthrough, (L), and $M$ is the mass of nanostructured adsorbent, $(\mathrm{g})$.

\subsection{Characterization}

The surface morphology and size of nanostructured adsorbent was obtained from TEM using a JEOL JEM 2100 instrument, which at $200 \mathrm{kV}$ provides $0.27 \mathrm{~nm}$ point resolution. Analysis was carried out by placing a droplet of nanoparticle sample on a copper grid having 300 mesh size and $3 \mathrm{~nm}$ diameter covered with perforated carbon, followed by evaporating off the solvent under atmosphere. The chemical elements of samples were analyzed by using LEO SUPRA 35VP, SEM-EDS. The crystalline structures of samples were analyzed by powder xray diffraction (XRD) using a Bruker D5000 (Germany) diffractometer employing $\mathrm{Cu} \mathrm{K \alpha}$ radiation with $40 \mathrm{kV}$ and $30 \mathrm{~mA}$ at a scanning rate of $5^{\circ} \mathrm{C} / \mathrm{min}$. Thermogravimetric analysis of the samples was performed by model STA 409 PC Luxx, Netzsch at rate of $15^{\circ} \mathrm{C} / \mathrm{min}$ under Argon atmosphere. BET surface area analysis of samples were carried out at $77 \mathrm{~K}$ on a Tristar II 3020 , Micromeritics analyzer. The samples were outgassed at $300{ }^{\circ} \mathrm{C}$ for $3 \mathrm{~h}$ under a vacuum in the degas port of analyzer.

\section{Results and discussion}

\subsection{Characterization of nanostructured adsorbent}

The morphology of samples obtained using the TEM is shown in Fig. 2. The ETS-10 particles had a size ranging from 400-500 nm with well-defined square truncated bipyramid shape and flat surface (Fig. 2a) [30]. The morphology of prepared hollow carbon is shown in Fig. 2b-c. It was observed that uniform-sized carbon nanospheres interconnected into netlike loose structure. The magnified image shows that carbon nanosphere was in hollow cores. 
Lattice fringes were not clearly visible in the image. The maximum carbon nanoparticle size was found in the range of 10-30 $\mathrm{nm}$ with polyhedron structure [27]. Fig. 2d-e shows the images of 10 wt \% C@ETS-10 nanostructured adsorbent/nanosorbent. Carbon nanoparticles can be observed to be well dispersed onto ETS-10 surface. In addition, a large number of carbon nanoparticles do not have close contact with the surface of the ETS-10, possibly due to ionic charge on ETS-10 surface. In the absence of ETS-10, as-formed hollow carbon nanoparticles inclined to agglomerate. This suggests that ETS-10 acts as a support to control the agglomeration of the loose hollow carbon particles onto C@ETS-10, and supported carbon nanoparticles maintain their original shape and size without any aggregation.

Fig. 3 shows that the FE-SEM image of fresh 10 wt \% C@ETS-10 adsorbent pellet. It can be seen from Fig. 3a shows the $10 \mathrm{wt} \%$ hollow carbon polyhedron nanoparticles cover the surface of ETS-10. The sample was dense due to pressing of powder material during pellet preparation. The elemental composition of as-prepared fresh adsorbent was analyzed by energy dispersive spectroscopy, EDS (Fig. 3b). The spectrum revealed abundance of all anticipated constituents such as C (16.79 wt\%), Na (2.63 wt \%), Si (37.11 wt \%), Cl (0.98 wt\%), K (0.751 $\mathrm{wt} \%)$ and $\mathrm{Ti}(1.29 \mathrm{wt} \%)$. No other element was found in the fresh adsorbent indicating the high purity of the adsorbent. The silica amount was higher because HS-40 colloidal silica was used in pellet preparation.

Powder XRD analysis was conducted for fresh and used 10 wt \% C@ETS-10 pellets from the iodine capture experiments, and the results are shown in Fig. 4. Initially no iodine was present in fresh sample, as seen from the black colored pellets (Fig. 4a - left). Carbon and ETS10 sharp peaks can be seen in Fig. 4a. The carbon peaks were not clearly seen in the normal scan due to the low concentration of carbon on ETS-10, and/or the shielding of main peak of carbon at $25.3^{\circ}$ by the main peak of ETS-10 [31]. At slow scan carbon peaks were observed at $2 \theta=25.3^{\circ}$ and $43.5^{\circ}$ which represents the (002) and (101) plane of hexagonal structure of 
carbon (slow scan not shown) [28, 29]. Iodine adsorbed on pellets caused black color to turn dark yellowish (Fig. $4 \mathrm{~b}$ - right). The used pellets or $\mathrm{I}_{2}$-containing pellets were ground to a powder in a mortar-and-pestle apparatus powder for XRD analysis. Fig. 4b shows that iodine adsorbed on the pellets reduced the intensity of all the peaks of C@ETS-10.

Fig. 5 shows the thermogravimetric analysis of various samples performed from room temperature to $600{ }^{\circ} \mathrm{C}$. The total weight loss of $\sim 8.3 \mathrm{wt} \%$ observed for the ETS-10 sample includes a 7.0 wt \% loss due to the dehydration of loosely bound water from the ETS-10 framework up to $300{ }^{\circ} \mathrm{C}$. After this temperature, rate of weight loss was slow up to $550{ }^{\circ} \mathrm{C}$, mainly because of removal of water from the pores of ETS-10 [31]. Nanostructured carbon sample shows weight loss about $4.8 \mathrm{wt} \%$ due to removal of moisture as well as any impurities acquired during the refluxing step during its preparation. A pristine $10 \mathrm{wt} \%$ carbon loaded ETS-10 sample shows $6.5 \mathrm{wt} \%$ total weight loss. Approximately $4.8 \mathrm{wt} \%$ weight loss was observed due to removal of moisture from sample. Another potential cause of weight loss of adsorbent was the combined effect of carbon and ETS-10. At high temperature, carbon nanoparticles were removed from ETS-10 surface due to dehydration of ETS-10. The used sample showed $9.5 \mathrm{wt} \%$ weight loss. The iodine molecules adsorbed onto the sorbent pellets at two sites: (a) inside of sorbent pore, and (b) outer surface of sorbent. At initial period ( 15 min) up to $200{ }^{\circ} \mathrm{C}$, iodine sorbed on the outer surface and moisture desorb from the sorbent. Further weight loss of sample can be attributed to desorption of internally captured iodine from adsorbent.

Table 1 shows the BET surface area of ETS-10, carbon and 10 wt\% C@ETS-10 with pore volume and average pore diameter. Surface areas of as-prepared carbon (C) and ETS-10 were found to be 70 and $242 \mathrm{~m}^{2} \mathrm{~g}^{-1}$, respectively. BET surface area of C@ETS-10 sorbent increased with an increase in carbon loading onto support, ETS-10. The 10 wt\% C@ETS-10 sorbent was found to be a higher surface area $\left(149 \mathrm{~m}^{2} \mathrm{~g}^{-1}\right)$ than other carbon loadings. Further 
increase in carbon loading on the support actually resulted in a decreased surface area of the sorbent, possibly due to blockage of pore (Table 2); possibly due to aggregation of carbon polyhedron on ETS-10 surface at greater than $10 \mathrm{wt} \% \mathrm{C}$ loading on ETS-10. The average pore size of sorbent decreased with increasing carbon loading, indicating that supported carbon nanoparticles $(10-30 \mathrm{~nm})$ inserted into the pores of ETS-10 $(111.6 \mathrm{~nm})$.

\subsection{Iodine capture on various materials}

The performance evaluation of synthesized materials (carbon and ETS-10) and nanostructured adsorbents, C@ETS-10 for capture of gas phase iodine was conducted at 20 ${ }^{\circ} \mathrm{C}$. Fig. 6 shows the breakthrough curve of each sample $\left(C / C_{0}\right)$ plotted as a function of time. The adsorption capacity of each sample was calculated by integrating the area above the curve according to equation 1 . The empty column (no sorbent) breakthrough was achieved in $\sim 1 \mathrm{~h}$, the iodine amount sorbed into the system being negligible. Then, freshly prepared pellets of each sample were used in adsorption test. As seen from the breakthrough curves, the outlet iodine concentration was low at the beginning of the experiment, increasing gradually with time. Notably, black color of sorbent gradually changed into dark yellow from the bottom to the top providing a visual indication of iodine sorption. The results show that pure ETS-10 and carbon have lower iodine adsorption capacity, 5.5 and $11.5 \mathrm{mg} \mathrm{g}^{-1}$, respectively, compared to the 10 wt \% C@ETS-10 which had the iodine capture capacity of $28.9 \mathrm{mg} \mathrm{g}^{-1}$. ETS-10 has higher surface area and pore size, but lower iodine adsorption capacity, possibly due to higher adsorption-desorption rate of iodine molecules on sorbent (average pore size $-111.6 \mathrm{~nm}$ ). The average pore size of $10 \mathrm{wt} \% \mathrm{C} @ \mathrm{ETS}-10$ sorbent decreased to $39.0 \mathrm{~nm}$, most likely due to the deposition of carbon nanoparticles onto the ETS-10 surface and pores. The diameter of iodine molecule is $\sim 0.494 \mathrm{~nm}[32]$, which would be easily inserted into the pore of the sorbent.

After experimental run, the presence of iodine on adsorbent pellets was confirmed by SEM-EDS, as shown in Fig. 7. SEM image of used sorbent indicates a slight change in 
morphology as compared to fresh sample (Fig. 3). The orthorhombic/cubic crystal structure was observed on the surface of pellet. It is postulated that initially iodine molecules insert into the porous sites of adsorbent. When this sites would be blocked then vapors of iodine adsorb on the surface of adsorbent. Due to continuous flow of gas stream, maximum outer surface of pellet was come into contact with iodine stream therefore formation of thin layer on the sorbent, resulted formation of crystal on surface of pellet. EDS spectra of the used 10 wt \% C@ETS-10 were obtained to confirm the iodine presence on the adsorbent, and compared to the similar spectra of the fresh adsorbent. The new abundance of elemental iodine observed at $3.984 \mathrm{keV}$ due to presence of iodine (6.67 wt \%) onto the adsorbent (Fig. 7b).

\subsection{Effect of carbon loading on iodine capture}

Iodine removal capacity of different (3-30)wt \% C@ETS-10 was examined at $20{ }^{\circ} \mathrm{C}$ and is shown in Fig. 8. Iodine removal from gas stream was observed to increase with an increase in carbon loading on ETS-10 from 3 - $10 \mathrm{wt} \%$. A $10 \mathrm{wt} \%$ C@ETS-10 was found to have the highest adsorption capacity, $28.9 \mathrm{mg} \mathrm{g}^{-1}$, due to higher surface area of sample, $149 \mathrm{~m}^{2}$ $\mathrm{g}^{-1}$. But further increases in carbon percentages on ETS-10 showed a decrease in the iodine adsorption capacity. It might be possible that at higher carbon loading particles would be overlap on each other forming carbon clusters that block the active sites of sorbents. Therefore, the 10 wt \% C@ETS-10 was selected for studying the effects of additional parameters operating temperature and EBCT.

\subsection{Effect of temperature on iodine capture}

Fig. 9a shows the effect of adsorption temperature on the capture of iodine by $10 \mathrm{wt} \%$ C@ETS-10 by analyzing the breakthrough curves at temperatures ranging from $10-60{ }^{\circ} \mathrm{C}$ (after reprocessing of UNF, generated off-gas gets cooled to lower temperatures). The breakthrough point decreased with an increase in the temperature of the adsorption column. 
Fig. 9b shows the adsorption capacity of 10 wt\% C@ETS-10 calculated from equation 1 at different temperatures. The adsorption capacity gradually decreased with an increase in column temperature from $30.1 \mathrm{mg} \mathrm{g}^{-1}$ at $10{ }^{\circ} \mathrm{C}$ to $9.6 \mathrm{mg} \mathrm{g}^{-1}$ at $60{ }^{\circ} \mathrm{C}$. The similar trend was observed for carbon based sorbent (activated carbon) in previous literature [10]. The capacity at the lowest temperature, $10{ }^{\circ} \mathrm{C}$ was only $4 \%$ higher than that at $20{ }^{\circ} \mathrm{C}$. This is only a physical adsorption phenomena, in which iodine molecules adsorb on the surface of sorbent due to the van der Waals force of attraction. At the lowest temperature $\left(10^{\circ} \mathrm{C}\right)$, iodine would be condensing from the gas stream, therefore, $20^{\circ} \mathrm{C}$ was selected as the operating temperature to examine the effect of bed height.

\subsection{Effect of EBCT on iodine adsorption}

Possible effect of flow maldistribution in the column on iodine sorption capacity of sorbent was studied by varying the empty bed contact time (EBCT). The adsorption capacity of adsorbent was calculated from breakthrough curves at different EBCTs $(0.8-7 \mathrm{sec})$ at 20 ${ }^{\circ} \mathrm{C}$. The breakthrough and exhaustion times increased with increasing EBCT of sorbent. Fig. 10a shows the iodine sorption capacity of adsorbent for different EBCTs. At very low EBCT $(0.8 \mathrm{sec})$, the sorbent saturated rapidly, and yielding adsorption capacity of $24.2 \mathrm{mg} \mathrm{g}^{-1}$. The sorbent capacity was $28.9 \mathrm{mg} \mathrm{g}^{-1}$ at EBCT $1.4 \mathrm{sec}$, and it gradually increased with EBCT of sorbent. A higher capacity of adsorbent (39.3 $\left.\mathrm{mg} \mathrm{g}^{-1}\right)$ was observed at higher EBCT (7 seconds). These results suggested that (a) observed sorbent capacity increases linearly with EBCT, and (b) sorbent capacity is approaching a limiting maximum value at high EBCT. These two statements indicate a Langmuir isotherm type relationship between observed capacity and EBCT of adsorbent. The maximum (limiting) sorbent capacity was calculated by linearizing the relationship as shown below [33]:

$$
\left(\frac{1}{Q_{\mathrm{e}}}\right)=\left(\frac{1}{Q_{\mathrm{m}}}\right)+\left(\frac{1}{\mathrm{~K}_{\mathrm{L}} \mathbf{Q}_{\mathrm{m}} \mathrm{t}}\right)
$$


where, $\mathrm{Q}_{\mathrm{m}}=$ maximum adsorption capacity $\left(\mathrm{mg} \mathrm{g}^{-1}\right), \mathrm{Q}_{\mathrm{e}}=$ equilibrium observed capacity $(\mathrm{mg}$ $\left.\mathrm{g}^{-1}\right), \mathrm{t}=$ bed contact time of adsorbent $(\mathrm{sec}), \mathrm{K}_{\mathrm{L}}=$ characteristic adsorption constant

The adsorption capacity $\left(\mathrm{Qm}_{\mathrm{m}}\right)$ was found to be $40 \mathrm{mg} \mathrm{g}^{-1}$ from linear plot of $1 / \mathrm{Q}_{\mathrm{e}} \mathrm{vs} 1 / \mathrm{t}$ (Fig. 10b).

\subsection{Comparison of sorbent}

Table 3 shows the comparison of iodine adsorption capacity of different sorbents obtained from breakthrough experiments. The results indicate that the as-prepared C@ETS-10 achieved good iodine adsorption capacity at low temperature. But, the capacity of prepared sorbent was quite lower than other reported sorbents. The higher adsorption capacity of other sorbents may be due to high surface area of sorbent. The silver impregnated sorbent formed the chemical reaction with iodine, therefore, it has higher sorbent capacity than any other sorbents [34].

\section{Conclusions}

Active C@ETS-10 sorbent was prepared via wet-impregnation technique. The performance of material/sorbent for iodine sorption was evaluated using the continuous adsorption column at different process conditions such as temperature, carbon loading and bed height. The maximum iodine adsorption capacity of sorbent was calculated using Langmuir isotherm, and found to be $40 \mathrm{mg} \mathrm{g}^{-1}$ at $20{ }^{\circ} \mathrm{C}$. Notable that without any chemical reaction/bonding C@ETS-10 sorbent adsorbs efficient amount of iodine from the gas stream based on specific surface area. C@ETS-10 sorbent is cheaper and easy to prepare as compare to reported sorbents (silver-alumina, zeolite, MOFs). The experimental results indicate that C@ETS-10 is active sorbent for capture of volatile radioiodine from off-gas stream, which would be helpful to protect the environment from the growth of nuclear energy.

\section{Acknowledgements}


We are grateful for financial support from US Department of Energy - Nuclear Energy University Program (Project No.: DE-NE0000660).

\section{References}

[1] L. Sjoberg, Explaining individual risk perception: The case of nuclear waste, Risk Manag. 6 (2004) 51-64.

[2] D. F. Sava, M. A. Rodriguez, K. W. Chapman, P. J. Chupas, J. A. Greathouse, P. S. Crozier, T. M. Nenoff, Capture of volatile iodine, a gaseous fission product, by zeolitic imidazolate framework-8, J. Am. Chem. Soc. 133 (2011) 12398-12401.

[3] International Commission on Radiation Protection, Recommendations of the ICRP, ICRP Publication 26, Ann. ICRP, 1, 1977.

[4] National Council on radiation protection and measurement; Recommendations on limits for exposure to lionizing radiation, NCRP 91, (1987) 1929.

[5] Environmental radiation protection requirements for normal operations of activities in the Uranium Fuel Cycle, Environmental Protection Agency, U.S. EPA. 40 CFR 190, Washington, D.C., 2012.

[6] J. Zhou, S. Hao, L. Gao, Y. Zhang, Study on adsorption performance of coal based activated carbon to radioactive iodine and stable iodine, Ann. Nucl. Energy 72 (2014) 237-241.

[7] K. Munakata, S. Nanjo, S. Yamatsuki, A. Koga, D. Ianovski, Adsorption of noble gases on silver-mordenite, J. Nucl. Sci. Technol. 40 (2003) 695-697.

[8] H. K. Lee, G. I. Park, Adsorption characteristics of elemental iodine and methyl iodide on base and TEDA impregnated carbon, J. Korean Nucl. Soc. 28 (1996) 44-55.

[9] J. Gan, N. E. Megonnell, S. R. Yates, Adsorption and catalytic decomposition of methyl bromide and methyl iodide on activated carbons, Atmos. Environ. 35 (2001) 941-947. 
[10] G. I. Park, B. S. Choi, I. H. Cho, J. H. Kim, S. K. Ryu, Adsorption and desorption characteristics of methyl iodide on silver ion-exchanged synthetic zeolite at high temperature, J. Korean Nucl. Soc. 32 (2000) 504-513.

[11] T. Fukasawa, K. Funabashi, Y. Kondo, Separation technology for radioactive iodine from off-gas streams of nuclear facilities, J. Nucl. Sci. Technol. 31 (1994) 1073-1083.

[12] T. Sakurai, A. Takahashi, M. Ye, T. Kihara, S. Fujine, Trapping and measuring radioiodine (Iodine - 129) in cartridge filters, J. Nucl. Sci. Technol. 34 (1997) 211-216.

[13] J. Matyas, R. K. Engler, Assessment of methods to consolidate iodine-loaded silverfunctionalized silica aerogel, Pacific Northwest National Laboratory, PNNL-22874, 2013.

[14] L. Wu, J.A. Sawada, D.B. Kuznicki, T. Kuznicki, S. M. Kuznichi, Iodine adsorption on silver-exchanged titania-derived adsorbents, J. Radioanal. Nucl. Chem. 302 (2014) 527532.

[15] B. J. Riley, J. Chun, J. V. Ryan, J. Matyas, X. S. Li, D. W. Matson, S. K. Sundaram, D. M. Strachan, J. D. Vienna, Chalcogen-based aerogels as a multifunctional platform for remediation of radioactive iodine, RSC Adv. 1 (2011) 1704-1715.

[16] B. J. Riley, J. Chun, W. Um, W. C. Lepry, J. Matyas, M. J. Olszta, X. Li, K. Polychronopoulou, M. G. Kanatzidis, Chalcogen-based aerogels as sorbents for radionuclide remediation, Environ. Sci. Technol. 47 (2013) 7540-7547.

[17] B. J. Riley, D. A. Pierce, J. Chun, J. Matyas, W. C. Lepry, T. G. Garn, J. D. Law, M. G. Kanatzidis, Polyacrylonitrile-chalcogel hybrid sorbents for radioiodine capture, Environ. Sci. Technol. 48 (2014) 5832-5839.

[18] K. S. Subrahmanyam, D. Sarma, C. D. Malliakas, K. Polychronopoulou, B. J. Riley, D. A. Pierce, J. Chun, M. G. Kanatzidis, Chalcogenide aerogels as sorbents for radioactive iodine, Chem. Mater. 27 (2015) 2619-2626. 
[19] A. P. Katsoulidis, J. He, M. G. Kanatzidis, Functional monolithic polymer organic framework aerogel as reducing and hosting media for Ag nanoparticles and application in capturing of iodine vapors, Chem. Mater. 24 (2012) 1937-1943.

[20] M.-H. Zeng, Q.-X. Wang, Y.-X. Tan, S. Hu, H.-X. Zhao, L.-S. Long, M. Kurmoo, Rigid pillars and double walls in a porous metal-organic framework: Single-crystal to singlecrystal, controlled uptake and release of iodine and electrical conductivity, J. Am. Chem. Soc. 132 (2010) 2561-2563.

[21] D. F. Sava, T. J. Garino, T. M. Nenoff, Iodine confinement into metal-organic frameworks (MOFs): Low-temperature sintering glasses to form novel glass composite material (GCM) alternative waste forms, Ind. Eng. Chem. Res. 51 (2012) 614-620.

[22] J. T. Hughes, D. F. Sava, T. M. Nenoff, A. Navrotsky, Thermochemical evidence for strong iodine chemisorption by ZIF-8, J. Am. Chem. Soc. 135 (2013) 16256-16259.

[23] A. Sigen, Z. Yuwei, L. Zhongping, X. Hong, X. Ming, L. Xiaoming, M. Ying, Highly efficient and reversible iodine capture using a metalloporphyrin-based conjugated microporous polymer, Chem. Commun. 50 (2014) 8495-8498.

[24] G. Massasso, M. Rodriguez - Castillo, J. Long, A. Grandjean, B. Onida, Y. Guari, Ch. Guerin, J. Larionova, Nanocomposites based on Hofmann-type structure Ni ${ }^{\mathrm{II}}(\mathrm{pz})\left[\mathrm{Ni}{ }^{\mathrm{II}}\right.$ $\left.(\mathrm{CN})_{4}\right](\mathrm{pz}=$ pyrazine $)$ nanoparticles for reversible iodine capture, J. Mater. Chem. A, 3 (2015) 179-188.

[25] F. Belloni, C. Kutahyali, V. V. Rondinella, P. Carbol, T. Wiss, A. Mangione, Can carbon nanotubes play a role in the field of nuclear waste management?, Environ. Sci. Technol. 43 (2009) 1250-1255.

[26] S. M. Kuznicki, Large-pored crystalline titanium molecular sieve zeolites, US Pat 4853 202, 1989. 
[27] X. Yang, R. E. Truitt, ${ }^{129}$ Xe NMR investigation of ETS-10 titanosilicate molecular sieves, J. Phys. Chem. 100 (1996) 3713-3718.

[28] S. U. Nandanwar, K. Coldsnow, V. Utgikar, P. Sabharwall, D. E. Aston, Y. Zhang, Synthesis and characterization of ETS-10 - supported hollow carbon nano-polyhedrons nanosorbent for adsorption of krypton at near ambient temperatures, Adsorption, (2015), DOI 10.1007/s10450-015-9702-8.

[29] Y. Zhu, Y.-J. Bai, N. Lun, Y.-X. Qi, R. Liu, H.-L. Zhu, Low temperature preparation of hollow carbon nano-polyhedrons with uniform size, high yield and graphitization, Mater. Chem. Phys. 134 (2012) 639-645.

[30] X. Yang, J.-L. Paillaud, H. F. W. J. van Breukelen, H. Kessler, E. Duprey, Synthesis of microporous titanosilicate ETS-10 with $\mathrm{TiF}_{4}$ or $\mathrm{TiO}_{2}$, Microporous Mesoporous Mater. $46(2001) 1-11$.

[31] K. P. Prasanth, H. C. Bajaj, H. D. Chung, K. Y. Choo, T. H. Kim, R. V. Jasra, Hydrogen sorption in transition metal modified ETS-10, Int. J. Hydrogen Energy 34 (2009) 888896.

[32] A. J. Juhola, Iodine adsorption and structure of activated carbons, Carbon 13 (1975) 437442.

[33] I. Langmuir, The adsorption of gases on plane surfaces of glass, mica and platinum, J. Am. Chem. Soc. 40 (1918) $1361-1403$.

[34] D. T. Pence, F. A. Duce, W. J. Maeck, Application of metal zeolites to nuclear fuel reprocessing plant off-gas treatment, Trans. ANS 15 (1972) 96. 


\section{Table Captions}

Table 1 Properties of samples.

Table 2 BET surface area of the different C@ETS-10 sorbents.

Table 3 Comparison of the iodine sorption of various sorbents.

\section{Figure Captions}

Fig. 1. Schematic diagram of lab scale iodine adsorption experimental apparatus.

Fig. 2. TEM images of (a) ETS-10, (b-c) hollow carbon nano-polyhedrons, C (d-e) 10 wt \% C@ETS-10 adsorbent.

Fig. 3. (a) SEM image (b) EDS spectra of fresh 10 wt \% C@ETS-10 adsorbent pellet.

Fig. 4. P-XRD of (a) fresh (b) used pellets of $10 \mathrm{wt} \% \mathrm{C} @ \mathrm{ETS}-10$ and their photograph.

Fig. 5. TGA of as-synthesized samples (a) ETS-10 (b) Carbon (c) Fresh and (d) Used 10 wt \% C@ETS-10 adsorbent.

Fig. 6. Breakthrough curve vs time for ETS-10, carbon and $10 \mathrm{wt} \%$ C@ETS-10 adsorbents. Experimental conditions: Gas flowrate $=150 \mathrm{~mL} \mathrm{~min}^{-1} ; C_{0}$ (iodine) $=32 \pm 3 \mathrm{PPM} ; 1.0 \mathrm{~g}$ of sorbent $(\mathrm{EBCT}-1.4 \mathrm{sec})$; temperature of adsorption column $=20^{\circ} \mathrm{C}$.

Fig. 7. (a) SEM image (b) EDS spectra of used $10 \mathrm{wt} \%$ C@ETS-10 for iodine capture.

Fig. 8. Effect of carbon loading on capture of iodine. Experimental conditions: Gas flowrate =

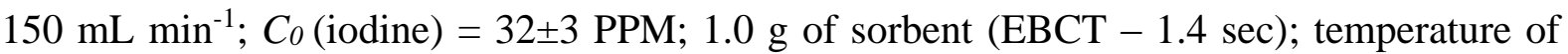
adsorption column $=20^{\circ} \mathrm{C}$.

Fig. 9. (a) Breakthrough curve and (b) Iodine adsorption capacity of $10 \mathrm{wt} \%$ C@ETS-10 at different temperatures. Experimental conditions: Gas flowrate $=150 \mathrm{~mL} \mathrm{~min}{ }^{-1} ; C_{0}$ (iodine) $=$ $32 \pm 3 \mathrm{PPM} ; 1.0 \mathrm{~g}$ of sorbent $(\mathrm{EBCT}-1.4 \mathrm{sec})$; Carbon loading $=10 \mathrm{wt} \%$.

Fig. 10. (a) Effect of EBCT on iodine adsorption (b) Linear fir for Langmuir model for iodine adsorption on 10 wt \% C@ETS-10. Experimental conditions: Gas flowrate $=150 \mathrm{~mL} \mathrm{~min}{ }^{-1}$; 
$C_{0}($ iodine $)=32 \pm 3$ PPM; Carbon loading $=10 \mathrm{wt} \%$; temperature of adsorption column $=20$ ${ }^{\circ} \mathrm{C}$. 
Table 1

\begin{tabular}{llll}
\hline Name & $\begin{array}{l}\text { BET Surface area } \\
\left(\mathrm{m}^{2} \mathrm{~g}^{-1}\right)\end{array}$ & $\begin{array}{l}\text { Average Pore size } \\
(\mathrm{nm})\end{array}$ & $\begin{array}{l}\text { Pore volume } \\
\left(\mathrm{cm}^{3} \mathrm{~g}^{-1}\right)\end{array}$ \\
\hline Carbon & 70 & 22.6 & 0.79 \\
ETS-10 & 242 & 111.6 & 0.05 \\
$10 \mathrm{wt} \%$ C@ETS-10 & 149 & 39 & 0.072 \\
\hline
\end{tabular}

Table 2

\begin{tabular}{ll}
\hline Name & $\begin{array}{l}\text { BET Surface area } \\
\left(\mathrm{m}^{2} \mathrm{~g}^{-1}\right)\end{array}$ \\
\hline $3 \mathrm{wt} \%$ C@ETS-10 & 104 \\
$5 \mathrm{wt} \%$ C@ETS-10 & 118 \\
$20 \mathrm{wt} \%$ C@ETS-10 & 145 \\
$30 \mathrm{wt} \%$ C@ETS-10 & 76 \\
\hline
\end{tabular}

Table 3 


\begin{tabular}{|c|c|c|c|c|c|}
\hline Sorbent & $\begin{array}{l}S^{a} \\
\left(\mathrm{~m}^{2} \mathrm{~g}^{-1}\right)\end{array}$ & $\begin{array}{l}\text { Co(Iodine) } \\
(\mathrm{PPM})\end{array}$ & $\begin{array}{l}\text { Temp. } \\
\left({ }^{\circ} \mathrm{C}\right)\end{array}$ & $\begin{array}{l}\operatorname{COS}^{b}\left(\mathrm{mg} \mathrm{g}^{-1}\right) / \\
\text { Recovery (\%) }\end{array}$ & Ref. \\
\hline Activated carbon & 1420 & - & $>50$ & 320 & $10^{\dagger}$ \\
\hline Zeocarbon & 820 & - & $>50$ & 100 & $10^{\dagger}$ \\
\hline $\begin{array}{l}\text { Silver-Exchanged zeolite } \\
(\mathrm{AgZ}-10 \mathrm{wt} \%)\end{array}$ & 795 & - & 150 & 117 & $10^{\dagger}$ \\
\hline $\begin{array}{l}\text { Silver-impregnated alumina } \\
(\mathrm{AgA}-24 \mathrm{wt} \%)\end{array}$ & 10 & 750 & $\geq 100$ & 220 & 11 \\
\hline $\begin{array}{l}\text { Silver-impregnated silica gel } \\
(\mathrm{AgS}-12 \mathrm{wt} \%)\end{array}$ & - & 1223 & 150 & $\begin{array}{l}\sim 75 \\
\left(1^{\text {st }} \text { Filter }\right)\end{array}$ & 12 \\
\hline $\begin{array}{l}\text { Chalcogen-based aerogels } \\
(\mathrm{Pt}-\mathrm{Ge}-\mathrm{S})\end{array}$ & 490 & 4.2 & $\sim 140$ & $99 \%$ & 15 \\
\hline $\begin{array}{l}\text { Chalcogen-based aerogels } \\
(\mathrm{SnS})\end{array}$ & 456 & 4.2 & 125 & $>99 \%$ & 16 \\
\hline C@ETS-10 (10 wt\%) & 149 & $32 \pm 3$ & 20 & 40 & This work \\
\hline
\end{tabular}




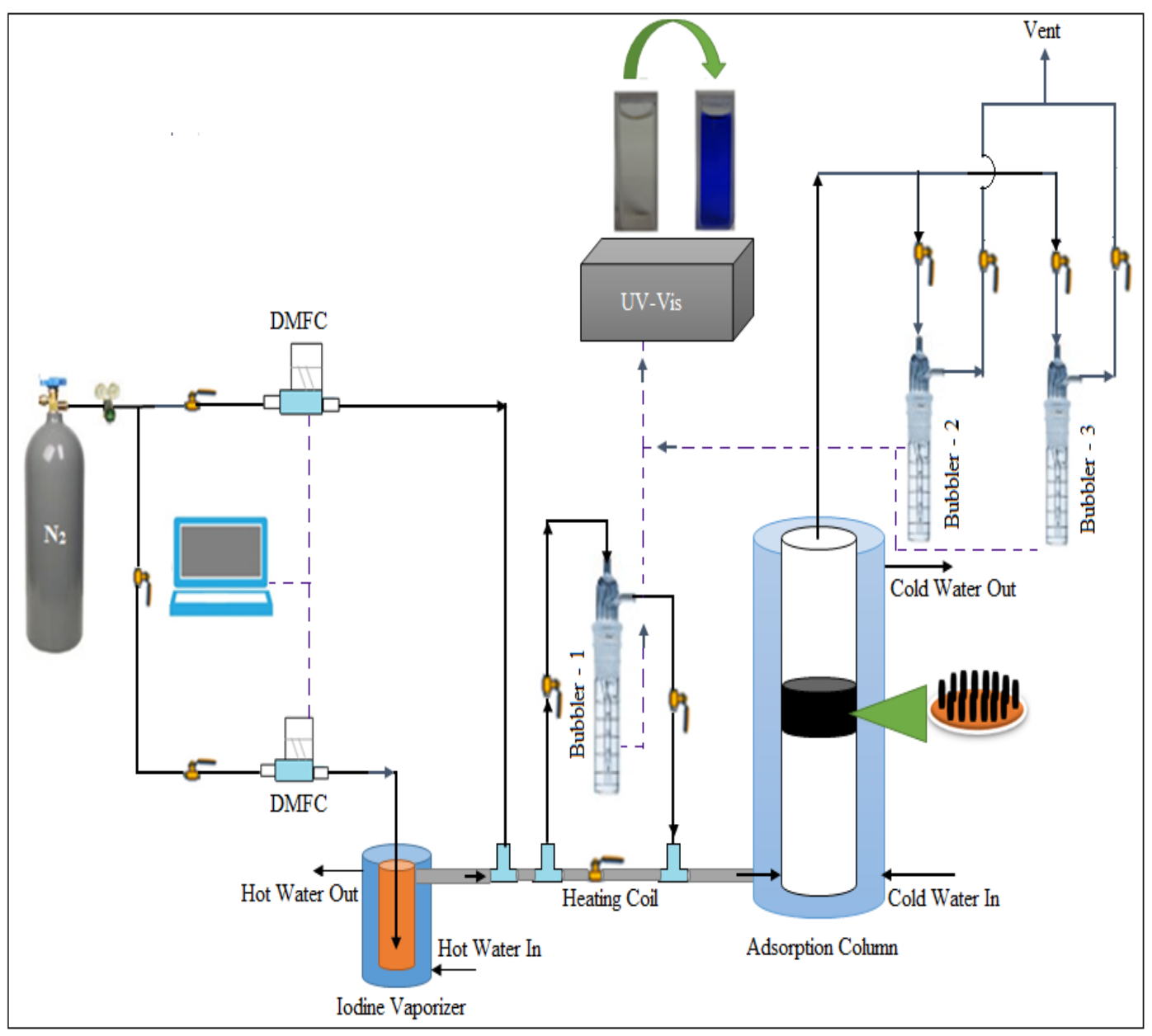

Fig. 1. 


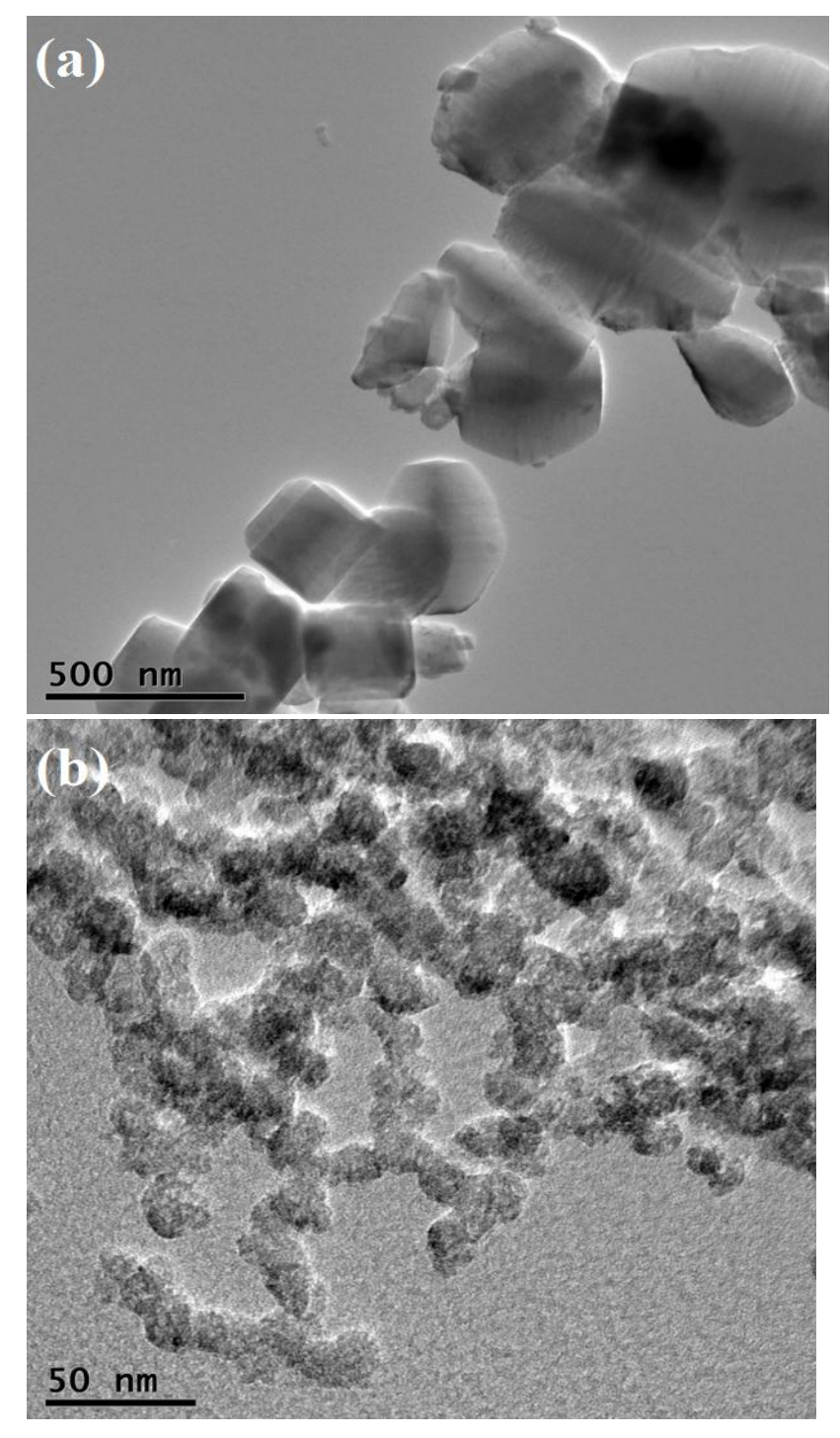



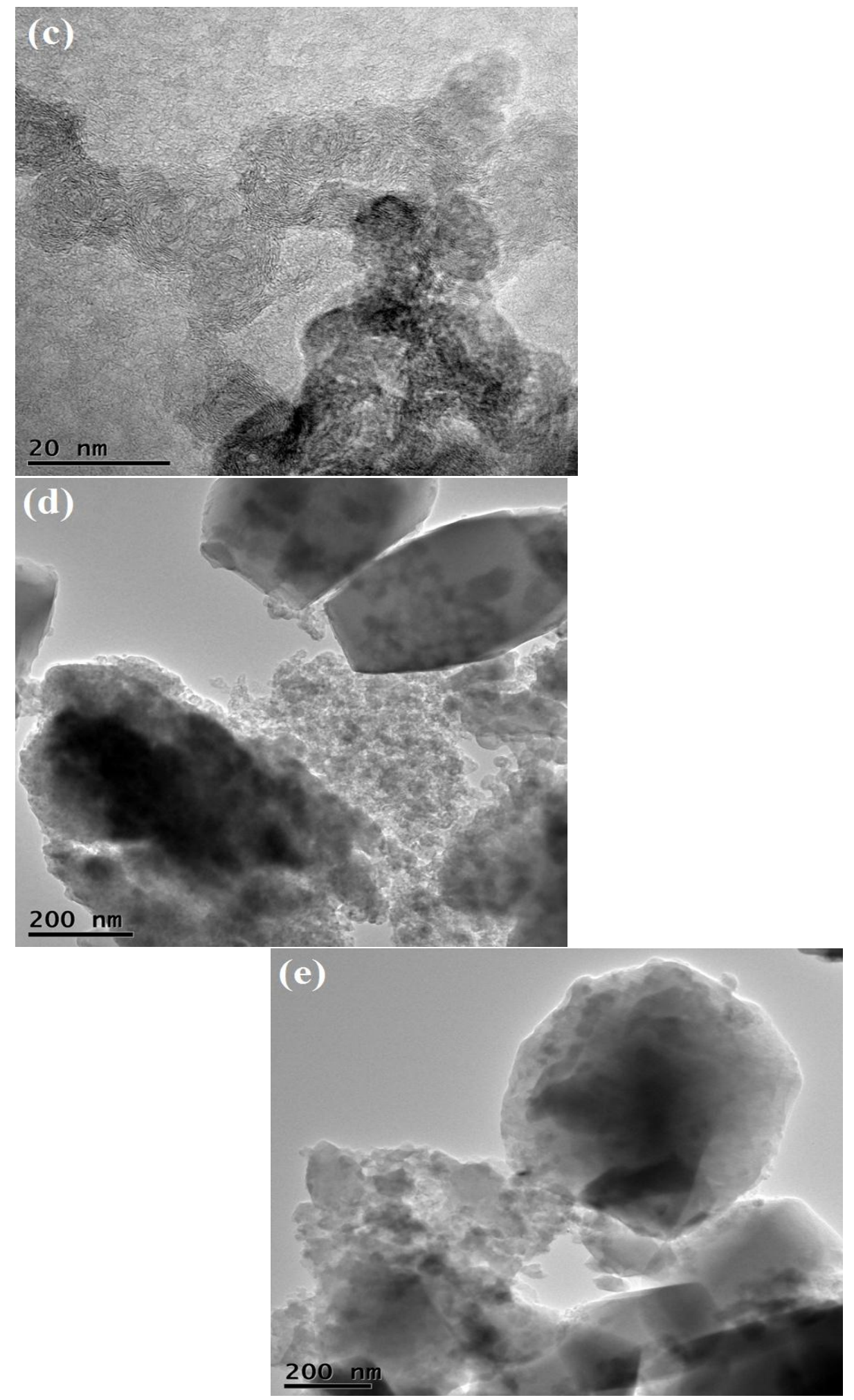

Fig. 2. 

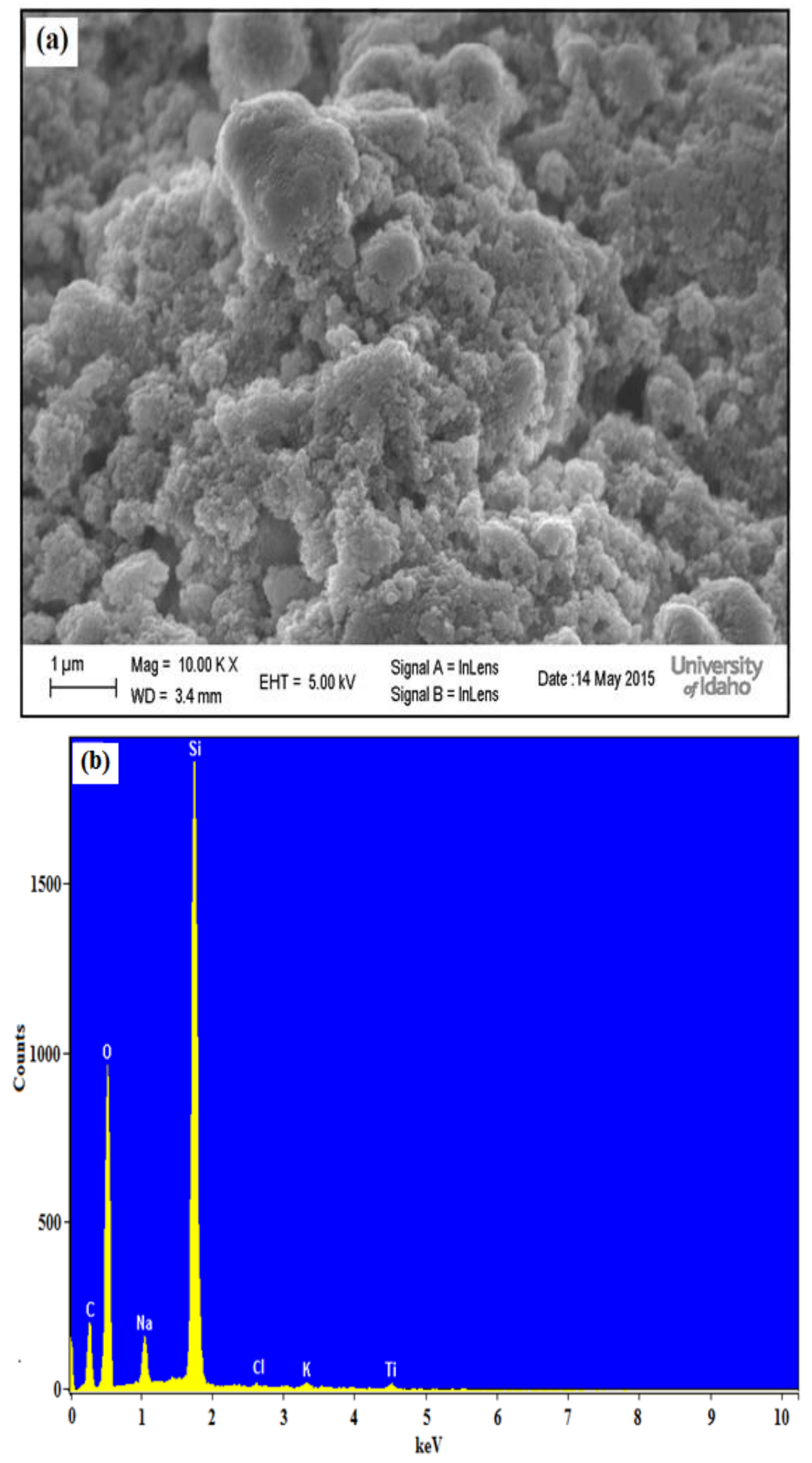

Fig. 3. 


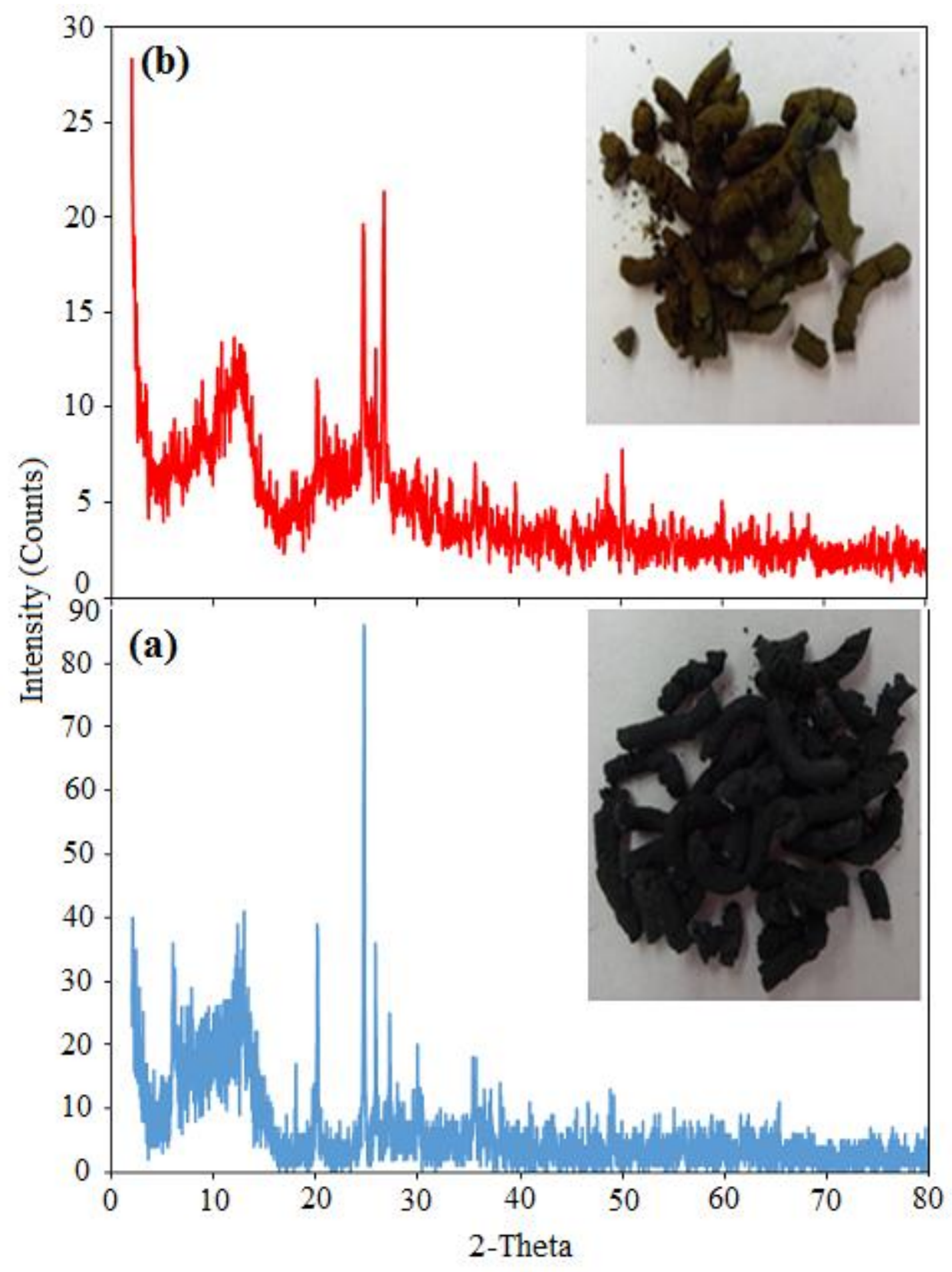

Fig. 4. 


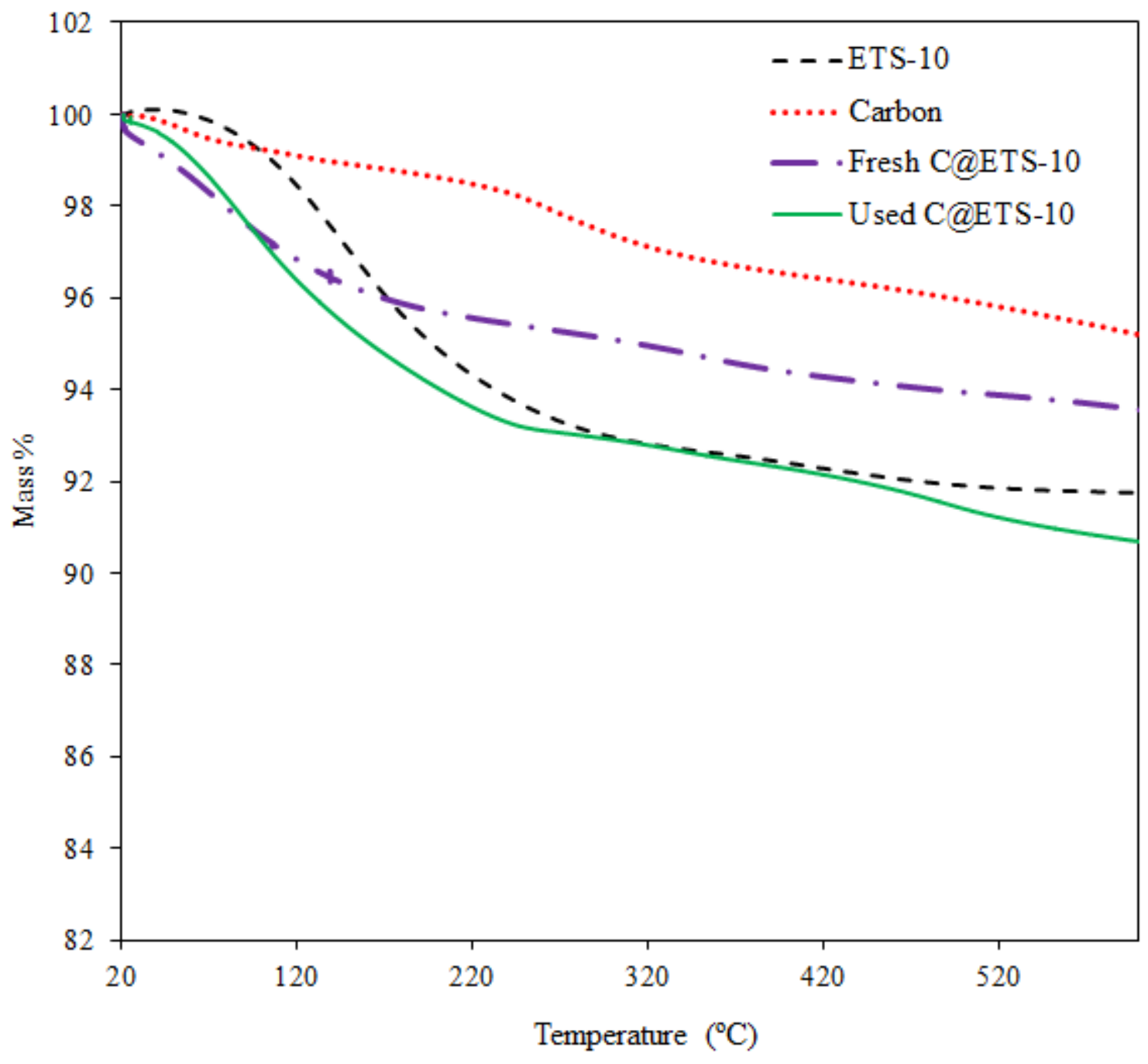

Fig. 5. 


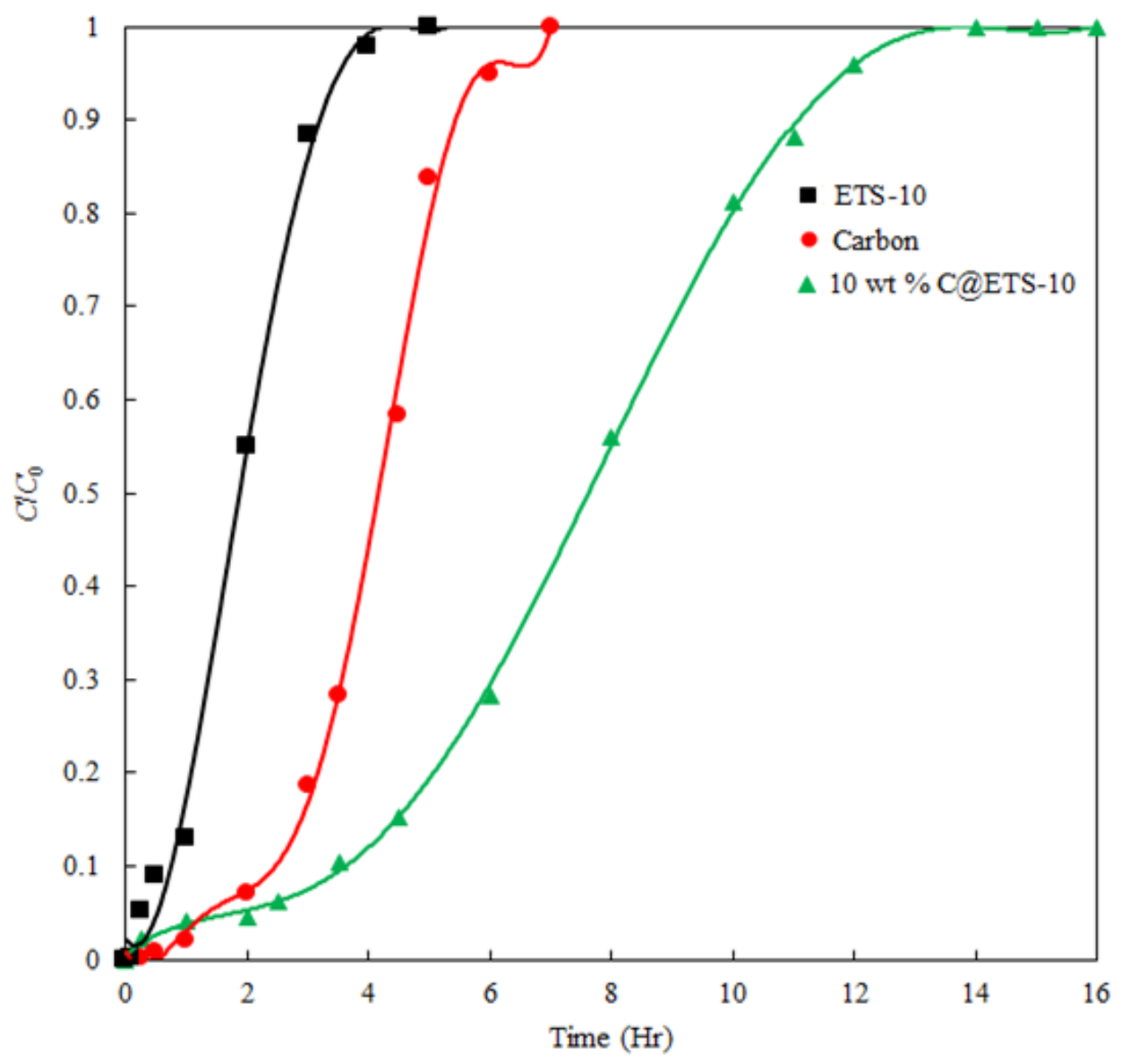

Fig. 6. 

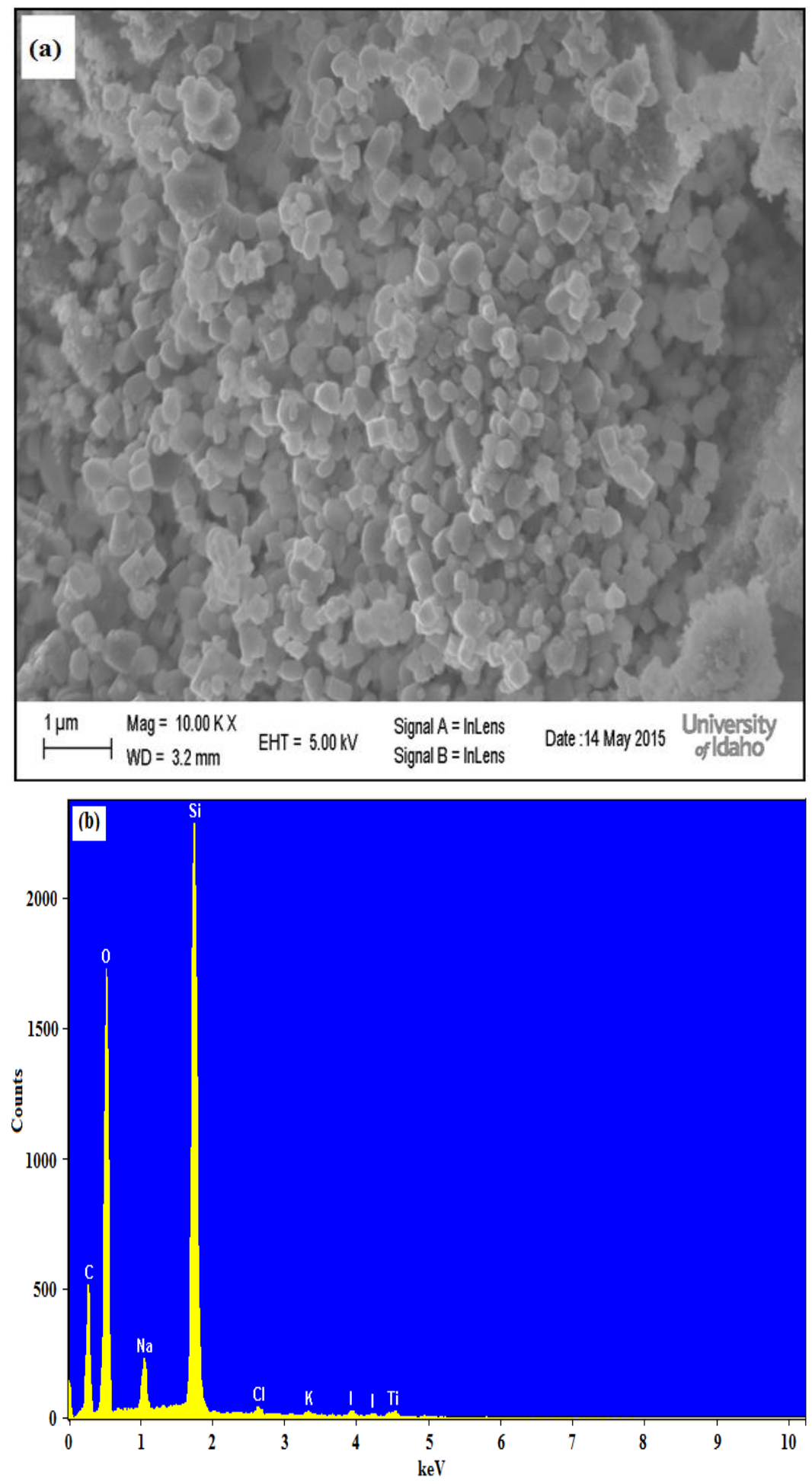

Fig. 7. 


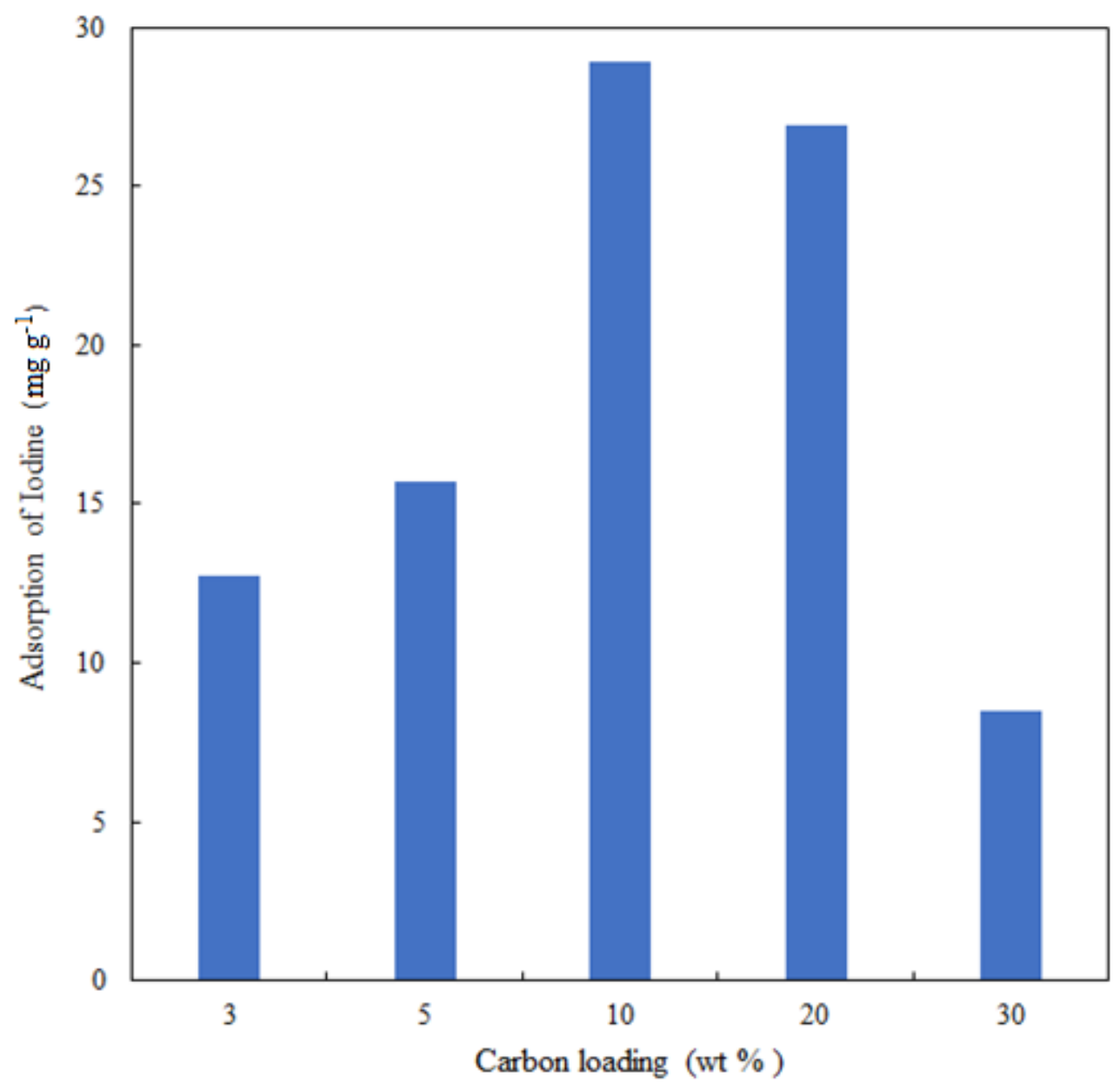

Fig. 8. 

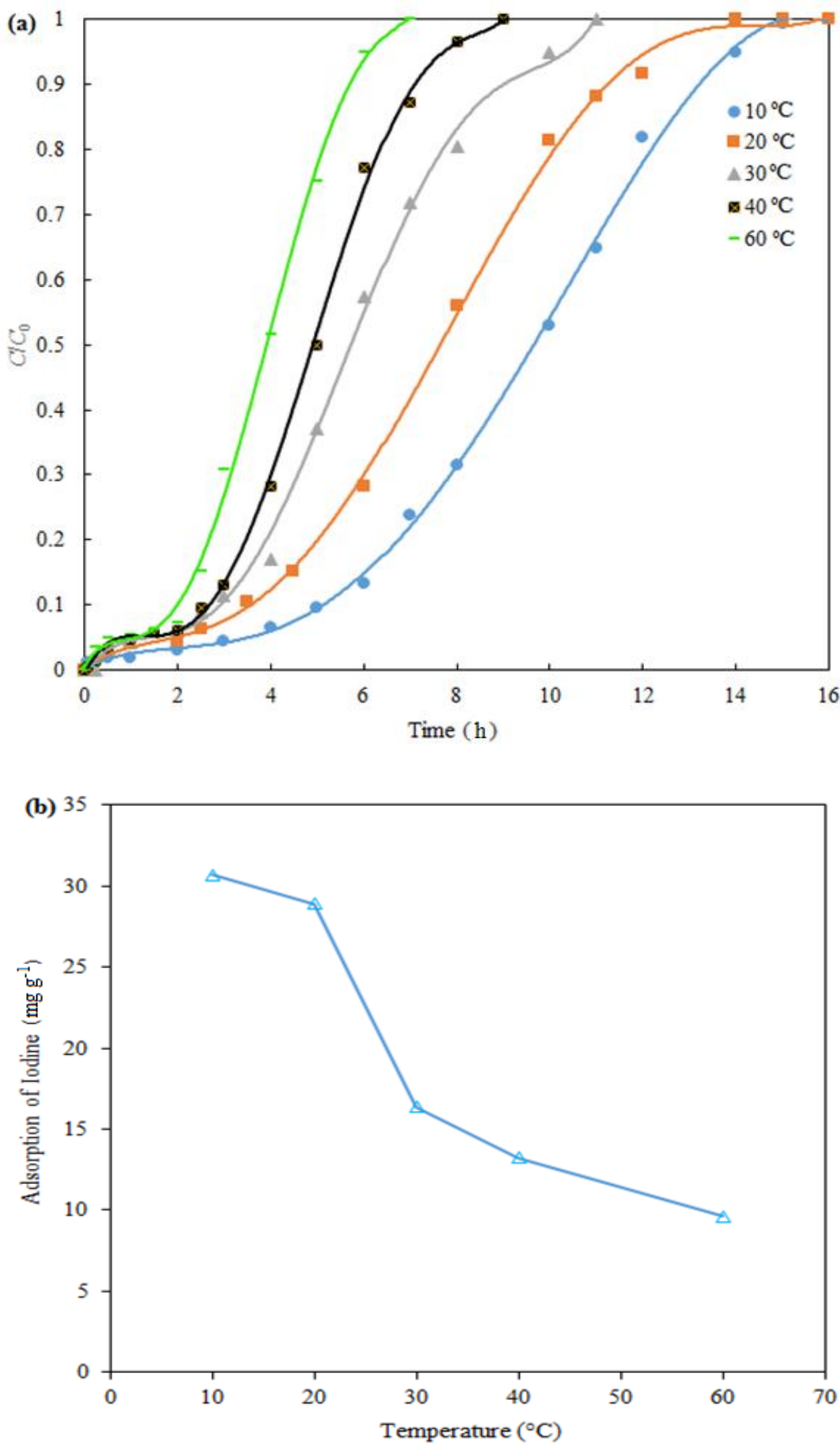

Fig. 9. 

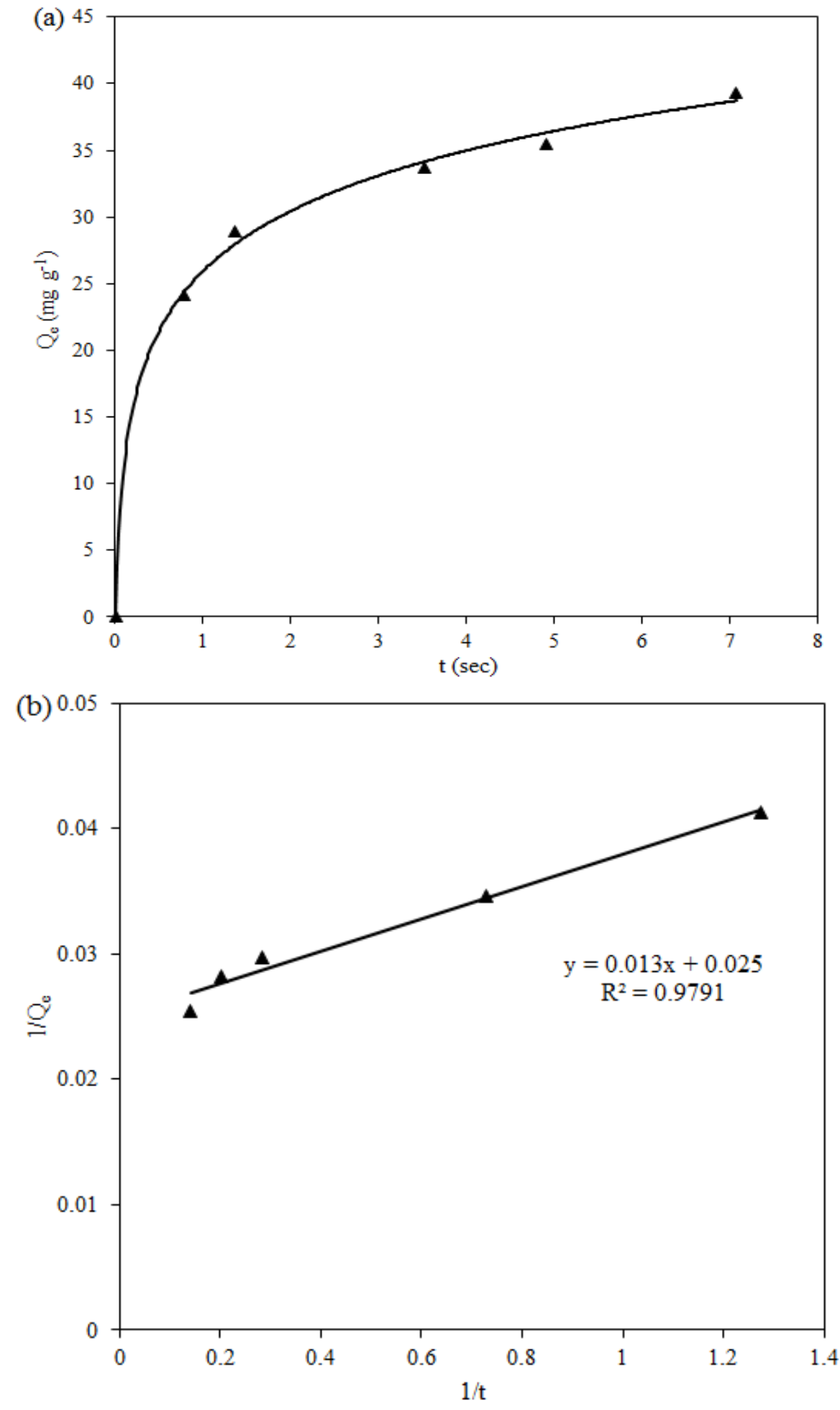

Fig. 10. 